\title{
OBSERVATION OF LONG TERM TRENDS IN THE AMOUNT OF ATMOSPHERIC WATER VAPOR BY SPACE GEODESY AND REMOTE SENSING TECHNIQUES
}

\author{
R. Haas, T. Ning, G. Elgered \\ Chalmers University of Technology \\ Department of Earth and Space Science \\ Onsala Space Observatory
}

\begin{abstract}
We present long term trends in the amount of atmospheric water vapor at the Swedish West Coast. These trends are derived from geodetic Very Long Baseline Interferometry (VLBI), ground based microwave radiometry, and radiosonde observations. The time span of observations covers 25 years and the data were collected at the Onsala Space Observatory (VLBI and microwave radiometry) and the Gothenburg-Landyetter Airport (radiosondes). The three techniques detect positive trends in the integrated precipitable water vapor (IPWV) on the order of 0.4 to $0.6 \mathrm{~kg} / \mathrm{m}^{2}$ per decade. The IPWV data derived from the three techniques have correlation coefficients on the order of 0.95 and better. However, there is no perfect agreement between the IPWV trends derived by the three techniques. This might partly be explained by different temporal sampling and data gaps.
\end{abstract}

Index Terms - Integrated precipitable water vapor, geodetic VLBI, microwave radiometry, radiosondes

\section{INTRODUCTION}

The amount of atmospheric water vapor and the corresponding temporal and spatial variation is of major interest for meteorology and climate research. Consistent time series of integrated precipitable water vapor (IPWV) are therefore valuable data sets for these research areas. Since variations in the amount of atmospheric water vapor might have a connection to anthropogenically influenced climate change scenarios, the observation of IPWV variations is also of major interest to society.

A number of different observation techniques are sensitive to the amount of atmospheric water vapor and thus can be used to monitor IPWV variations. For example, more than a decade of radiosonde data have been used to derive IPWV trends [1]. Long-term trends in the IPWV have also been derived from more than 15 years of ground based microwave radiometry observations [2]. In recent years space geodetic techniques have been used to derive trends in atmospheric water vapor. Both, results based on geodetic VLBI data analysis, e.g. [3], [4], and also GPS data analysis, e.g. [5] [6], [7], [8], [9], have been presented.

Since there are technique specific advantages and disadvantages in terms of instrumental stability, measurement uncertainty, temporal and spatial sampling, a comparison of the results derived from co-located sensors is of interest. We focus on the data obtained with different co-located techniques operated at the Onsala Space Observatory at the Swedish west coast. The observatory hosts equipment for both geodetic VLBI and microwave radiometry and data for more than two decades have been collected with these two techniques. The observatory also is equipped with instrumentation for GNSS observations and GNSSdata have been collected for more than a decade. In about $37 \mathrm{~km}$ distance to the observatory radiosondes are launched at the Gothenburg-Landvetter Airport since more than two decades.

To investigate trends in the amount of atmospheric water vapor we concentrate on long time series and thus focus on the results for IPWV derived from the three techniques that have observational history of more than two decades.

\section{OBSERVATIONS AND DATA ANALYSIS}

The Onsala Space Observatory is actively contributing to high quality geodetic VLBI observations since the 80'ies of the last century [10]. Usually 20 to 30 individual VLBI sessions are performed per year, and additionally a number of continuous campaigns have been observed. However, the observing sessions are unfortunately not on regular intervals and thus the amount of atmospheric water vapor is not sampled regularly with VLBI. On the other hand does the VLBI techniques promise long term stability due to its stable instrumentation. 
A global VLBI data set was analyzed covering January 1984 to the end of 2008 using the CALC/SOLVE software [11]. Radio source positions, station positions and velocities were estimated as global parameters, and earth rotation and orientation parameters as daily parameters. The necessary no-net-translation and no-net-rotation constraints were applied. Clock parameters and zenith wet delay (ZWD) parameters were estimated as piece-wise linear functions with a $1 \mathrm{~h}$ resolution, and horizontal atmospheric gradients as piece-wise linear functions with a $3 \mathrm{~h}$ resolution. Solid earth tides, ocean loading and atmospheric loading were applied in the analysis. An elevation cutoff angle of 5 degrees and the NMF mapping functions [12] were used. The resulting ZWD values were converted to IPWV applying the formalism described in [13].

A water vapor radiometer (WVR) is used at the Onsala Space Observatory to perform mircrowave radiometry measurements since 1980 [14]. It is a two channel instrument (21.0 and $31.4 \mathrm{GHz})$ with horn antennas with an opening angle of 6 degrees. Before 1993 the instrument was mainly operated only during VLBI observations. After that it is used almost continuously in a so-called sky-mapping mode. There were several repair and upgrade periods in 1991/1992, 2003 and 2006/2007, respectively, when the instrument unfortunately was not operating.

The acquired data were analyzed using the in house developed RadGrad software and zenith wet delays and gradients were estimated with a temporal resolution of 30 minutes. The ZWD results were then converted to IPWV as described before.

Radiosondes (RS) are a traditional measurement device for upper air observations in meteorology. The closest radio launch station to the Onsala Space Observatory is at the Gothenburg-Landvetter airport where the Swedish Meteorological and Hydrological Institute (SMHI) launches radiosondes. These measurements have a long and continuous observation history, however the launching interval has varied over the years between 6,12 and 24 hours and also the type of radiosondes has changed over the years. Before March 1986 the radiosonde type Vaisala RS18 was in use and since December 1985 the radiosonde type Vaisala RS80 is in use. Both types were used in parallel during an overlapping period of four months.

Radiosonde data are available as atmospheric profiles of pressure, temperature, and humidity. The data were analyzed using the in house developed CalcRS software, and finally were IPWV results derived. The accuracies are assumed to be 5\% of the absolute value, based on measurement accuracies of the sensors used in the radiosondes [15].

\section{COMPARISON OF IPWV TIME SERIES}

Time series of IPWV derived from VLBI, WVR and RS data analysis are presented in Fig. 1. We concentrate on the period 1984 to the end of 2008 where all three techniques have observations. The RS derived IPWV time series is most regularly sampled, while both the VLBI and WVR derived IPWV time series have some gaps. Seasonal signatures are clearly visible in all three time series and a seasonal model that includes six parameters (offset, rate, cosine and sine amplitudes of an annual and a semi-annual period) can be fitted independently to each data set. Table 1 show the derived IPWV trends.

Since the original data have different temporal sampling we also synchronized the data sets pairwise. The three original data sets were reduced to three pairs of synchronized data sets where the time difference of the data points between the two data sets is not longer than 1 hour.

Scatterplots of the pairwise synchronized data are shown in Fig. 2. The data sets are highly correlated with correlation coefficients above 0.95. Again, the seasonal model was fitted to the synchronized data sets and the trend results are shown in Table 1. Table 2 shows mean IPWV values, mean IPWV differences and the RMS differences for the three synchronization pairs.

\section{CONCLUSIONS AND OUTLOOK}

The results presented in Table 1 show that all three techniques detect positive trends in IPWV on the order of 0.4 to $0.6 \mathrm{~kg} / \mathrm{m}^{2}$ per decade. However, the individual trends do not agree. The formal errors presented are too optimistic and have to be inflated by a factor of 5-10 to represent more realistic uncertainties.

A major problem in the comparison is the different sampling of the three data sets and the data gaps. The attempt to synchronize the data sets has a significant impact on both the number of data points used in the analysis and the derived IPWV trends. There are only small biases of less than $1 \mathrm{~kg} / \mathrm{m}^{2}$ between the synchronized IPWV results, and the RMS-differences are below $2 \mathrm{~kg} / \mathrm{m}^{2}$. However, the synchronized IPWV data sets have different trends than the original data sets. These changes are not completely understood yet. In particular appears the pairwise synchronization of the VLBI data with the other two data sets increase the disagreement between the derived trends. On the other hand, appears the pairwise synchronization of the RS data with the other two data sets increase the agreement between the derived trends. This effect is unexpected and so far unexplained and needs further investigation. 

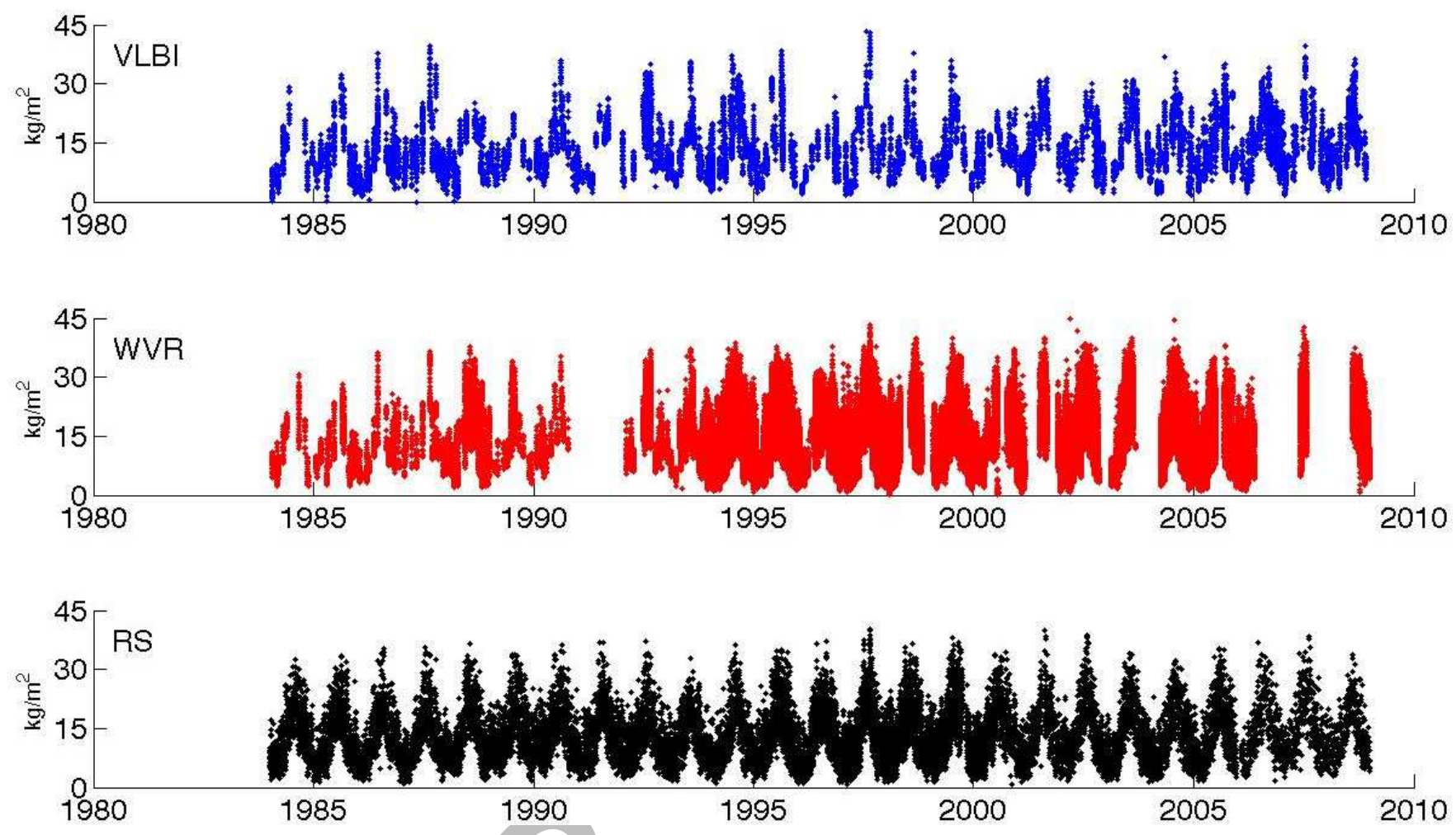

Fig. 1. Time series of integrated precipitable water vapor (IPWV) as determined from geodetic VLBI data observed at Onsala (VLBI, top) microwave radiometry at Onsala (WVR, middle) and radiosondes at Gothenburg-Landvetter (RS, bottom).

Table 1. Results for linear IPWV trends inferred from geodetic VLBI and microwave radiometer (WVR) data from Onsala, and radiosonde (RS) data from Gotheburg-Landvetter airport. The uncertainties represent formal errors and are too optimistic by a factor of $5-10$.

\begin{tabular}{|c|c|c|}
\hline $\begin{array}{l}\text { Data } \\
\text { source }\end{array}$ & $\begin{array}{l}\text { Data } \\
\text { points }\end{array}$ & $\begin{array}{c}\text { IPWV trend } \\
\left(\mathrm{kg} / \mathrm{m}^{2} / \text { decade }\right)\end{array}$ \\
\hline \multicolumn{3}{|c|}{ unsynchronized (all) data Jan. 1984 - Dec. 2008} \\
\hline VLBI & 15188 & $0.61 \pm 0.03$ \\
\hline WVR & 299642 & $0.53 \pm 0.10$ \\
\hline RS & 21669 & $0.45 \pm 0.03$ \\
\hline \multicolumn{3}{|c|}{ synchronizing VLBI and WVR } \\
\hline VLBI & 9047 & $0.85 \pm 0.04$ \\
\hline WVR & 9047 & $0.56 \pm 0.04$ \\
\hline \multicolumn{3}{|c|}{ synchronizing VLBI and $R S$} \\
\hline VLBI & 1138 & $0.65 \pm 0.10$ \\
\hline $\mathrm{RS}$ & 1138 & $0.45 \pm 0.10$ \\
\hline \multicolumn{3}{|c|}{ synchronizing $W V R$ and $R S$} \\
\hline WVR & 7947 & $0.67 \pm 0.05$ \\
\hline RS & 7947 & $0.52 \pm 0.05$ \\
\hline
\end{tabular}

Future work will concentrate on methods to integrate and combine the data sets in order to derive robust estimates of potential IPWV trends. 

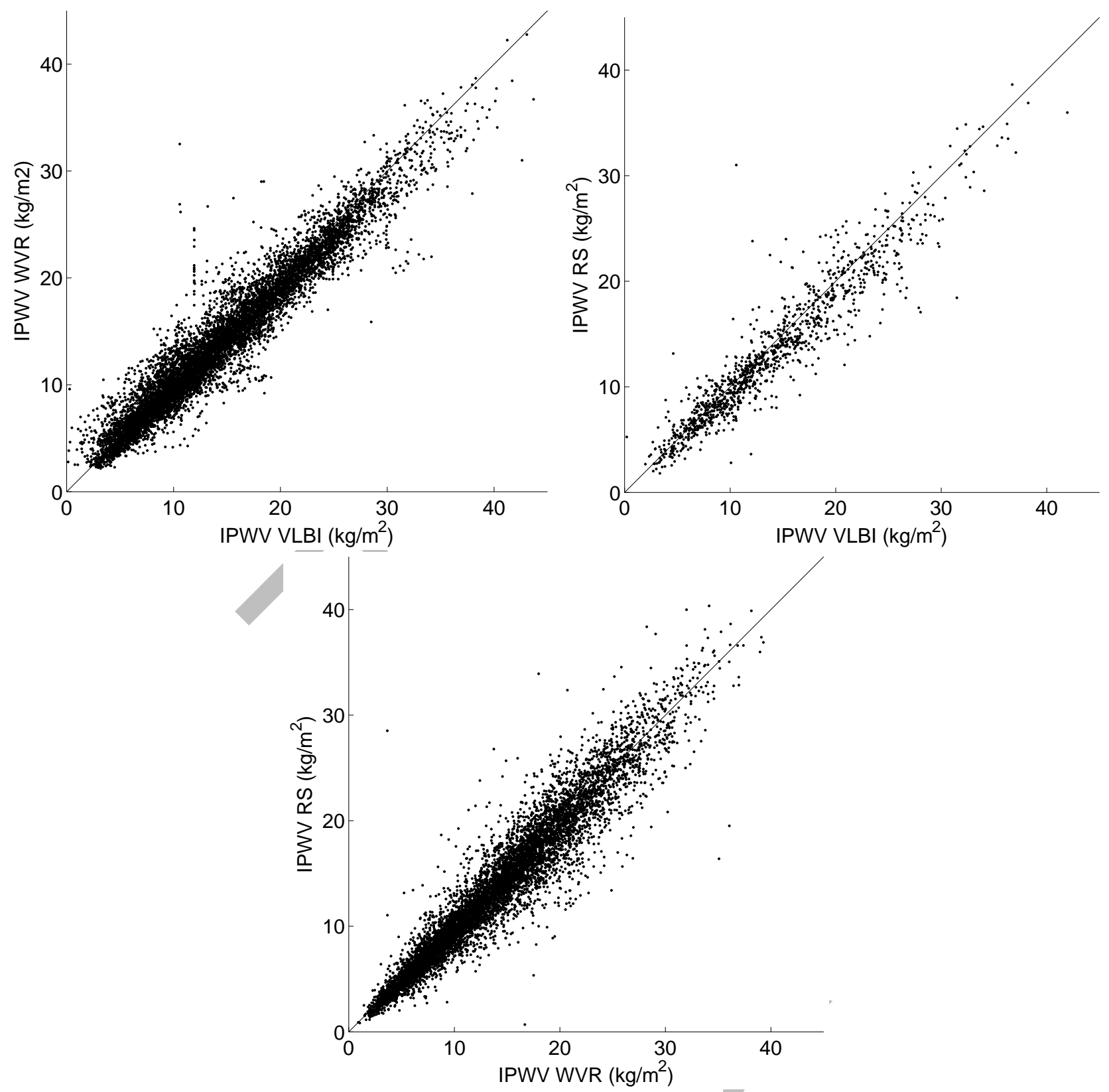

Fig. 2. Scatterplots of synchronized IPWV: WVR versus VLBI (top), RS versus VLBI (middle) and RS versus WVR (bottom). The correlation coefficients are $0.96,0.95$ and 0.96 , respectively.

Table 2. Comparison of synchronized IPWV data: Mean IPWV of the first technique, mean IPWV difference, and RMS difference.

\begin{tabular}{lccc}
\hline $\begin{array}{l}\text { Synhronized } \\
\text { Comparison }\end{array}$ & $\begin{array}{c}\text { Mean IPWV } \\
\left(\mathrm{kg} / \mathrm{m}^{2}\right)\end{array}$ & $\begin{array}{c}\Delta \mathrm{IPWV} \\
\left(\mathrm{kg} / \mathrm{m}^{2}\right)\end{array}$ & $\begin{array}{c}\text { RMS } \\
\left(\mathrm{kg} / \mathrm{m}^{2}\right)\end{array}$ \\
\hline VLBI vs. WVR & 14.20 & $0.63 \pm 0.01$ & 1.55 \\
VLBI vs. RS & 14.04 & $0.70 \pm 0.05$ & 1.97 \\
WVR vs. RS & 13.86 & $0.52 \pm 0.01$ & 1.63 \\
\hline
\end{tabular}




\section{REFERENCES}

[1] D.J. Gaffen, W.P. Elliott, and A. Robock, "Relationships between tropospheric water vapor and surface temperature as observed by radiosondes," Geophysical Research Letters, vol. 19, pp. 1839-1842, Sept. 1992.

[2] G. Elgered and P.O.J. Jarlemark, "Ground-based microwave radiometry and long-term observations of atmospheric water vapor,” Radio Science, vol. 33, pp. 707-718, 1998.

[3] T.A. Herring, J.L. Davis, and I.I. Shapiro, "Geodesy by radio interferometry: The application of Kalman filtering to the analysis of very long baseline interferometry data," Journal of Geophysical Research, vol. 95, pp. 12561-12581, Aug. 1990 .

[4] R. Heinkelmann, J. Boehm, H. Schuh, S. Bolotin, G. Engelhardt, D.S. MacMillan, M. Negusini, E. Skurikhina, V. Tesmer, and O. Titov, "Combination of long time-series of troposphere zenith delays observed by VLBI," Journal of Geodesy, vol. 81, pp. 483-501, June 2007.

[5] D.M. Tralli and S.M. Lichten, "Stochastic estimation of tropospheric path delays in global positioning system geodetic measurements," Bulletin Geodesique, vol. 64, pp. 127-159, 1990.

[6] R.T. Emardson, G. Elgered, and J.M. Johansson, "Three months of continuous monitoring of atmospheric water vapor with a network of Global Positioning System receivers," Journal of Geophysical Research, vol. 103, pp. 1807-1820, 1998.

[7] L. Gradinarsky, J.M. Johansson, H.R. Bouma, H.-G. Scherneck, and G. Elgered, “Climate monitoring using GPS,” Physics and Chemistry of the Earth, vol. 27, pp. 335-340, 2002.

[8] G. Elgered, H.P. Plag, H. van der Marel, S. Barlag, and J. Nash (eds.), , in COST 716: Exploitation of ground-based GPS for climate and numerical weather prediction applications, Final Report. European Community, 2005, vol. ISBN 92-898-0012-7.

[9] T. Nilsson and G. Elgered, "Long-term trends in the atmospheric water vapor content estimated from ground-based GPS data," Journal of Geophysical Research (Atmospheres), vol. 113, pp. 19101, Oct. 2008.

[10] H.-G. Scherneck, "Space geodetic activities at the Onsala Space Observatory: 25 years in the service of plate tectonics," Physics and Chemistry of the Earth, vol. 23, pp. 811-823, 1998

[11] C. Ma, J.M. Sauber, T.A. Clark, J.W. Ryan, J.J. Bell, D. Gordon, and W.E. Himwich, "Measurement of horizontal motions in Alaska using very long baseline interferometry," Journal of Geophysical Research, vol. 95, pp. 21991-22011, Dec. 1990.

[12] A.E. Niell, "Global mapping functions for the atmosphere delay at radio wavelengths," Journal of Geophysical Research, vol. 101, pp. 3227-3246, 1996.

[13] R.T. Emardson and H.J.P. Derks, "On the relation between the wet delay and the integrated precipitable water vapour in the European atmosphere,” Meteorological Applications, vol. 7, pp. 61-68, Mar. 2000.

[14] G. Elgered, J.L. Davis, T.A. Herring, and I.I. Shapiro, "Geodesy by radio interferometry - Water vapor radiometry for estimation of the wet delay," Journal of Geophysical Research, vol. 96, pp. 6541-6555, Apr. 1991.

[15] M.N. England, F.J. Schmidlin, and J.M. Johansson, “Atmospheric Moisture Measurements: A Microwave Radiometer Radiosonde Comparison," IEEE Transactions of Geoscience and Remote Sensing, vol. 31(2), pp. 389-398, 1993. 